\title{
MODEL DEVELOPMENT FOR IN SITU TEST RESULTS
}

IN ARGILLACEOUS ROCK

L. D. Tyler

Sandia Laboratories*

Albuquerque, New Mexico 87185

\section{MSTR}

*This work was supported by the U.S. Department of Energy, DOE, under contract DE-ACO4-76DP00789.

${ }^{*}$ A U.S. DOE facility. 


\section{INTRODUCTION}

The development a-1 verification of mathematical models of repository performance are essential for risk assessment of geologic aisposal of nuclear waste. Two tasks basic to model development are:

1. Define phenomena and develop models for predicting repository behavior

2. Perform tests to evaluate and verify repository models. The strategy for accomplishing these tasks for determining the thermomechanical effects can be outlined as shown in Figure 1. Laboratory studies can provide data and preliminary phenomenological definition to allow scoping model. studies to be conducted. The results of these model studies provide guidance and definition of future investigations by establishing the issues that need to be resolved. The issues may require future labcratory effort or in situ tests. For in situ tests the scoping studies lead to design modeling for such tests. In situ tests may be conducted at shallow depths, of the order of tens of feet below the weathering zone, or at great $\geqq r$ depths, a few thousands of feet, which are more representative of a repository. The near surface in situ tests are conducted for two practical reasols: 1) lack of existing at-depth facilicies in the rock of interest and 2) cost for development of an at-depth facility. The near surface test does provide the in situ environment for developing constitutive and failure models which can be suissequently verified in at-depth tests. The at-depth 
tests not only verify constitutive and failure models but address more specific thermal/structural interaction problems needed for repcsitory design. Finally, the testing of the repository design models are conducted in a vault facility in conjunction with the specific repository site giving verification of the model for predicting repository behavior. To date, the work in argillaceous rock has progressed to the constitutive and failure model phase shown in the strategy of Figure 1. The results of near surface heater experiments in the Conasauga shale and Eleana argillite will be presented showing the resulting model development for the thermomechanical response. These models are then used to predict the at-depth behavior of argillaceous rock.

\section{SITE GEOLOGY AND ROCK PROPERTIES}

The near surface tests have been conducted in two very different geological settiags. The Conasauga experiment was conducted in shales within the Conasauga Formation at Oak Ridge, Tennessee and the Eleana test was conducted in argillite within the Eleana Formation on the Nevada Test Site, Nevada. The geologic description of the two formations are shown in the following table. 
GEOLOGIC CHARACTERIZATION OF NEAR SURFACE SITES

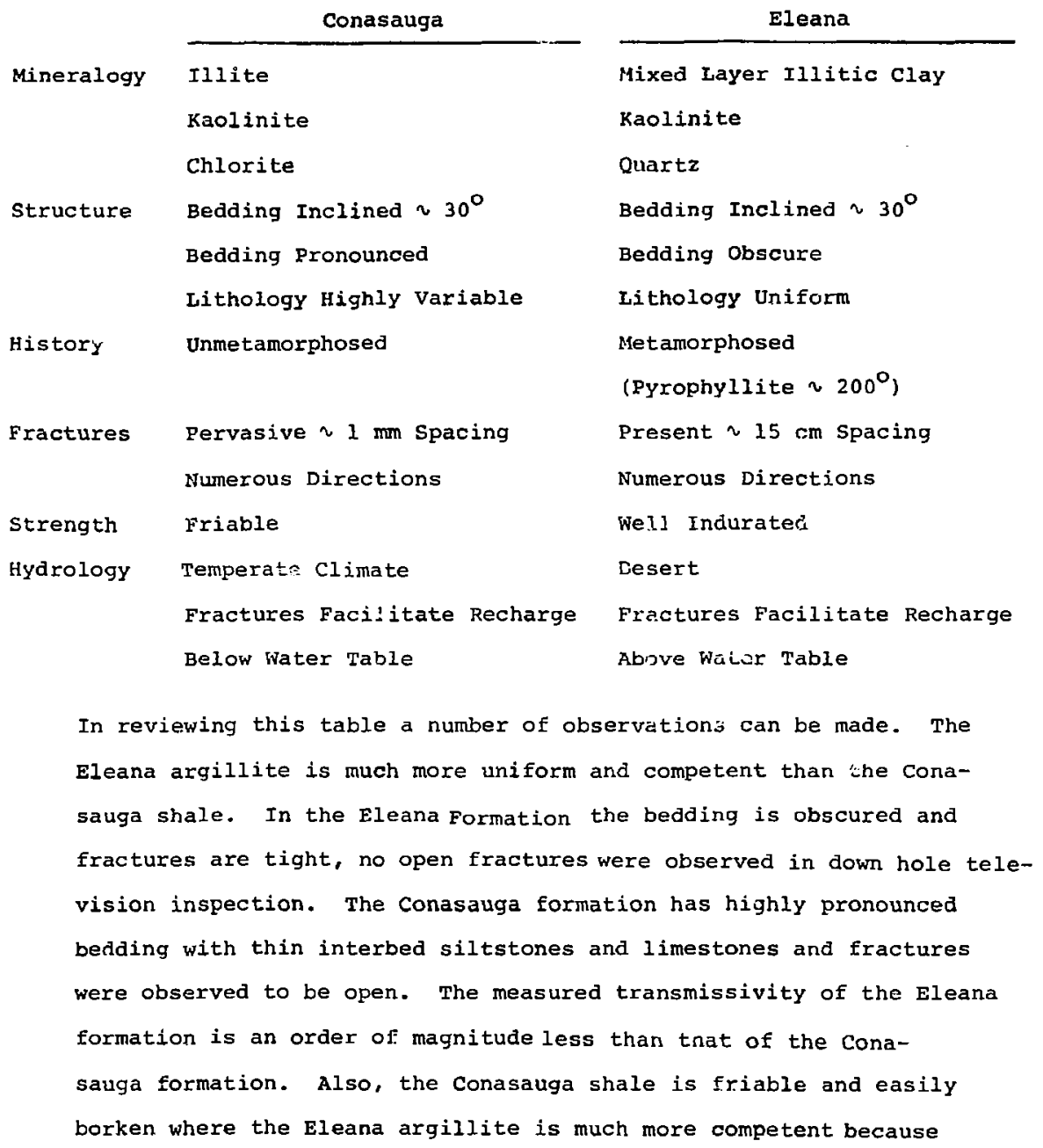


it has not been disrupted by shearing. A very important difference in the sites for the two experiments is the hydrology. The conasauga test was conducted below the water table in a temperate ciimate whereas the Eleana tegt was conducted above the water table in an arid climate.

The properties of the two rcaks have been measured in the laboratory and are sumarized below.

\section{PHYSICAI PROPERTIES}

Conasauga Siale

Eleana Argillite

Specific Heat
$\left(150-400^{\circ} \mathrm{C}\right)$
$0.8-1.0 \mathrm{~kJ} / \mathrm{Kg}^{\circ} \mathrm{C}$
$0.9-1.0 \mathrm{~kJ} / \mathrm{kg}^{\circ} \mathrm{C}$

Thermal Conductivity
$\left(25^{\circ} \mathrm{C}\right)$
$1.1-2.2 \mathrm{~W} / \mathrm{m}^{\circ} \mathrm{C}$
$2.0-2.6 \mathrm{~W} / \mathrm{m}^{\circ} \mathrm{C}$
$\left(125-500^{\circ} \mathrm{C}\right)$
$1.1-0.6 \mathrm{~W} / \mathrm{m}^{\circ} \mathrm{C}$
$2.0-1.3 \mathrm{~W} / \mathrm{m}^{\circ} \mathrm{C}$

Bulk Density

$\left(25^{\circ} \mathrm{C}\right.$ )

$2.6-2.7 \mathrm{gm} / \mathrm{cm}^{3}$

$2.7-2.9 \mathrm{gm} / \mathrm{cm}^{3}$

Water Content

(By Weight)

$1-38$

1. $B-4:$

Porosity

$0.1-48$

$6.8-128$

Thermal Expansion
$\left(150-450^{\circ} \mathrm{C}\right)$
$0.75-1.4 \times 10^{-5} /{ }^{\circ} \mathrm{C}$
$0.86-1.25 \times 10^{-5} /{ }^{\circ} \mathrm{C}$

The properties for the two rocks are very similar except the Eleana has a higher porosity and the Conasauga's thermal conductivity is lower than that of the Eleana. The variation with temperature of the thermal conductivity and thermal expansion are important to note because of the water present in the rocks. This water resides 
in the pore space and more importantly in the expandable clays in the "illite" present. The thermal conductivity shown in Figure 2 is for the Conasauga Shale. These data were measured for unconfined samples and show the reduction of conductivity due to water release with increasing temperature. In Figure 3 the thermal expassion ar a function of temperature for three Eleana samples is shown. For temperatures above $150^{\circ} \mathrm{C}$ the three samples show a continuous expansion with temperature as noted in the properties table. Below $150^{\circ} \mathrm{C}$, contraction of the rock occurs due to the water released from the expandable clays. The degree of contraction is dependent on the amount of clay present. The general dependence of thermal conductivity and thermal expansion on water release from expandable clays with increase in temperature has been seen for both the Conasauga Shale and the Eleana Argillite.

\section{FIELD TEST DESIGN}

The following section briefly describes the field test design for the near-surface tests with a brief discussion of operating conditions at the two sites. A generalized cross section of the heater emplacement configuration is shown in Figure 4 . The configuration was the same for both sites, with the heater being at a depth of 15 meters for the Conasauga test and 23 meters for the Eleana test.

The heater consists of a sealed, $0.3 \mathrm{~m}-\mathrm{diameter}$ cylinder of 304 stainless steel containing resistive heating elements, each rated at $6 \mathrm{~kW}$ maximum output. Each element is in the form of a 
hairpin loop about $3.7 \mathrm{~m}$ Iong, of which $3 \mathrm{~m}$ is heated, and consists of a nichrome resistance wire embedded in packed ceramic with an outer stainless steel sheath. Each heater contains six element loops wirea in two sets of three, such that three elements are operated simultaneously, with the second set constituting a backup.

The heater assembly contains three regions: 1) the heated region; 2) the cold section; and 3 ) the terminal or junction section. The heater region contains the $3 \mathrm{~m}$ long heated portion of the elements. The cold section contains the unheated (solid conductor) portions of the elements, and is filled with packed vermiculite. The terminal section, which contains the junction between the power leads and the solid conductor portion of the heater elements, is kept cool by air forced down the power lead conduit and up the thermocouple conduit.

As; shown in Figure 4, the heaters are emplaced in an open hole and are sealed off near the bottom of the casing by a pneumatic packer. To minimize heat and/or mass transfer in the area between the top of the heater and the bottom of the packer, fiberglas insulation is placed as near the top of the heater as practicable. Measurements made during th. heater experiments include peater and rock temperatures, stress, anu vertical displacement. Gas transmissivities were measured before and after the tests. The general plan view for the Eleana heater experiment is shown in Figure 5 and is essentially the same as for the Conasauga experiment. The sl-l hole is the heater hole and the satellite holes are used for instrumentation. The instrumentation used was thermocouple: for temperature, Invar extenstometers for displacement, and IPAD-Creare 
stress gauges for stress. In addition, spring-loaded thermocouples were attached to the heater in the Eleana test and measured heater hole wall temperatures directly.

The data acquisition systems used in the Conasauga and Eleana experiments were identical and used a Fluke data logger as the central element. Data were recorded by a sequential listing of all channels, and by magnetic tape.

Despite the similarity of their physical layouts, the procedures followed during operation of the Conasauga and Eleana experiments were quite different. The suter surface at the center plane of the Conasauga heater was brought up to constant temperature $\left(385^{\circ} \mathrm{C}\right)$ within the first week of operation. In order to prevent the heater from being florded by groundwater, it was necessary to pressurizo the heater hole with air, approximately equivalent to the hydrostatic head at the hole bottom. The full-scale Eleana experiment, after 21 days at $2.5 \mathrm{~kW}$, was run at a constant powar level of $3.8 \mathrm{kw}$. Initial operation of the heater indicated that small amounts of water present in the main heater hole were sufficient to seriously alter the heat transfer to the formation. Consequently, the heater was removed, a sump extension was drilled in the bottom of the heater hole to a total depth of $35 \mathrm{~m}$, and a passageway was excavated across to an adjacent hole, sl-3 (see Figure 5). At this point, the heater was again emplaced, and operation at $2.5 \mathrm{~kW}$ was continued. Water collecting in the sump $(51-1)$ was pirped out of $\mathrm{sl}^{-3}$ periodically for 45 days, at which time the water accumulation ceased. Since that time, the Eleana test has been operating in effectively "Ary" rock. 


\section{MODELING OF TEST RESULTS}

As a consequence of the differences in site geology, hydrology, and operating modes of the two tests, modeling efforts for the Eleana and Conasauga experiments have received somewhat different emphasis. The pattern followed in treating Conasauga data was to compare the quasi steady-state isotherms that developed after several months of heater operation with predictions based on simple conduction solutions, assuming constant heater temperature. Having done this, a comparison was made to determine whether or not the deviations noted could be ascribed to iluid convection in the formation. Since the Eleana experiment was run at constant power, the early-stage transient temperature build-up was and is a primary object of analysis of data from this test. Although the displacement data have not been analyzod the thermal behavior coupled with field examination of the heater hole surfaces for a scaled test and the full-scale test in the Eleana formation provide a basis for the thermomechanical moleling of the near surface experiment.

\section{Conasauga Model}

The Conasauga thermal data were analyzed by examining the temperature history distributtons, isotherms for given times, and the thermal input of the heater. Because the heater boundary condition for this test was a constant heater temperature the first thirty days of operation was at very high and variable heater power inputs to the formation. After thirty days and until the end of the experiment the power input slowly decayed as shown 
in Figure 6. At 240 days the power level has declined to a value of approximately $5.0 \mathrm{~kW}$. Examination of temperature distribution in the formation showed that only a small region close to the heater was above the boiling point of water and that most of the energy was transferred into saturated rock. Simple analytical models of heat conduction indicated that the energy was being distributed at a constant thermal conductivity of $1.8 \mathrm{~W} / \mathrm{m}^{\circ} \mathrm{C}$. This effective value of conductivity is consistent with the laboratory data at low temperatures as shown in Figure 2 .

This effective conductivity at elevated temperature is high with respect to values determined at the same temperature in the laboratory. The fact that in situ values lie in the range for the effective conductivities of unheated samples suggests that the calcuiated temperature profiles using a relatively constant conductivity should correspond to those profiles observed. $\Lambda$ parametric study was, therefore, made using the CINDA thermal code, a two-dimensional transient heat conduction code, with specified constant conductivities of 1.5 , 1.75 and $2.0 \mathrm{~W} / \mathrm{m}^{\circ} \mathrm{C}$. Heater temperatures were specified in accordance with those measured, and the void space between the heater top and the packer was assumed to have a constant wall temperature of $100^{\circ} \mathrm{C}$. A comparison of the predicted power values and those observed in the field indicates that a constant conductivity of about $2 \mathrm{~W} / \mathrm{m}^{\circ} \mathrm{C}$ can account for the power input, once the initial transient start-up phase has been concluded (Figure 6). A comparison between theoretical and actual isotherms shows that for those isotherms below the boiling point of water there is relatively good agreement (Figure 7) when a constant effective conductivity of $2 \mathrm{w} / \mathrm{m}^{\circ} \mathrm{C}$ is assumed.

\footnotetext{
Approximately $3 / 4 \mathrm{~kW}$ of the heater power is removed to the air which cools the heater leads.
} 
There is, however, a consistent slight upward displacement of the higher temperature isotherms in situ compared with those predicted by CINDA (Figure 7). In an attempt to determine if convective circulation could account for this displacement, the SHAFT code, a multidimensional porous flow code with two-phase flow capability, was run assuming a heater placed in a uniform isotropic porous media. The result of this modeling effort was a fluid flow and heat transfer pattern which, in a qualitative way, matches the difference inferred from, the comparison between the field data and conduction model output. An energy balance comparison between the field data and the heat conduction model showed very good agreement. To conclude, despite the presence of appreciable ground water and a fractured formation, j.t would appear that conduction is the principal method of heat tiansfer through the Conasauga formation in these terts. The fact that the effective in situ conductivity at elevated temperatures is considerably higher than that determined in the laboratory is consistent with the fact that during such lab determinations a sample becomes dried, and in doing so, has cracks open. It is probable that no dessication takes place in situ until temperatures in excess of $100^{\circ} \mathrm{C}$ are reached, and that even then the weight of the overburden is sufficient to close most small scale cracks. Thus, it is consistent that in situ conductivities would be close to the laboratory values measured for fresh unheated samples.

Eleana Model

Prior to running the full-scale heater test in the Eleana formation, two scaled heater tests were run to provide assurance 
that no ma;or thermomechanical failure of the argillite would occur to prevent i successful full scale, long-term heater test. Ir: the first test, scaled to a heater power of $3.5 \mathrm{kw}$, computed heater temperatures were within 78 of those measured for the entire 96 hour test. The second test, scaled to $5 \mathrm{~kW}$ power as an overtest, showed computed temperatures within 78 of measured for the first 20 hours but the measured temperatures were 15-20\% below prediction due to periodic water in-flow at late time in test. Posttest examination of the hole revealed that rock surface spallation had occurred above the heater. Using the thermal output from the finite element thermal code, COYOTE, as an input of the temperature field to the two-dimensional finite element thamal stress code, SASL, and modeling the contrartion-expansion behavior for argillite as shown in Figure 3, conpressive failure was predicted above and below the scaled heater as observed. since no major failure occurred in the scaled tests for the scaled power ınput of $3.5 \mathrm{~kW}$, the full-scale test was conducted. The energy transfer to the formation was modeled as heat conduction with variable thermal conductivity using the finite element thermal code, COYOTE. The comparison of measured and calculated temperatures for different radii from the heater showed good agreement for the first 100 days of operation. After that time the measured values increase above the predictions. Thermomechanical modeling of this test using the finite element code, ADINA, predicted that joint opening would occur in the rnck near the heater due to the contraction of the clays as water is released (Figure 8). The opening of joints would cause a reduction in the in situ thermal 
conductivity leading to higher temperature than predicted near the heater. Posttest examination of the full heater hole surface revealed an open joint system not present before formation leating. Sứmary

The results from the near-surface tests have provided development of thermal and thermomechanical models for argillaceous rock in two distinctly different geologies. The near-surface test results provide:

1. the definition of heat transfer models;

2. the modeling of thermally ariven water circulation; and

3. the definition of the joint opening model due to tise thermal contraction of argillaceous rock.

\section{AT-DEPTH PREDICTIONS}

Using the models developed from the near-surface tests, two studies have been made to predict the thermomechanical rock behavior at depth. The first study was an extension of the Eleana heater experiment to depths of approximately 1000 and 2000 meters using a Youngs modulus determined from laboratory measurements. The results of the calculations for 1000-meter deptis show that the region of joint opening is similar to the near-surface result but was less extensive, only occurring out to 0 ? meter radius instead of 1.1 meter. The results of the calculation for 2000meter depth show further reduction in the volume of the openjoint region about the heater. However, in this case compressive mechanical failure of the formation in a region above the heater is predicted. If one assumes the in situ Young's modulus is reduced by a factor of 2 to account for the joint system in the rock mass, 
the results of the calculations for $1000 \mathrm{~m}$ depth show no region in which open joints exist or where compressional failure would occur. Because of these differences in predicted behavior with depth, atdepth experiments are needed to determine the proper in situ properties and check the models. The second study compared the nearsurfact thermal stress fields with those predicted for a heater 7 meters below a tunnel floor at 425 meters depth. The results of the calculations showed only slight differences in the stress fields; significant differences were noted in the vertical displacement fielis above the heater due to the presence of the floor. The tensile strains observed for the near-surface calculation were reduced by the addition of the over-burden stress. This latter result is similar to the behavior observed above when the region of open joints was reduced by the addition of an overburden stress. These predictions made of at-depth behavior are based on near-surface tests rasults and need to be checked by at-depth experiments. This is particularly important since the near-surface test seems to maximize the open joint effect. Also, experiments are needed to determine if the compressive failure model applies at depths of interest.

vI. CONCLUSTONS

Near-surface heater tests have been conducted in two different geologic settings for argillaceous rocks. The results of these tests have provided the in situ data necessary to develop the thermomechanical models for predicting the response of argillaceous rock to thermal load representative of high-level nuclear 
waste. At depth tests would be required before full confidence could be given to the results. 


\section{FIGURE 1-- STRATEGY FOR MODEL VERIFICATION}

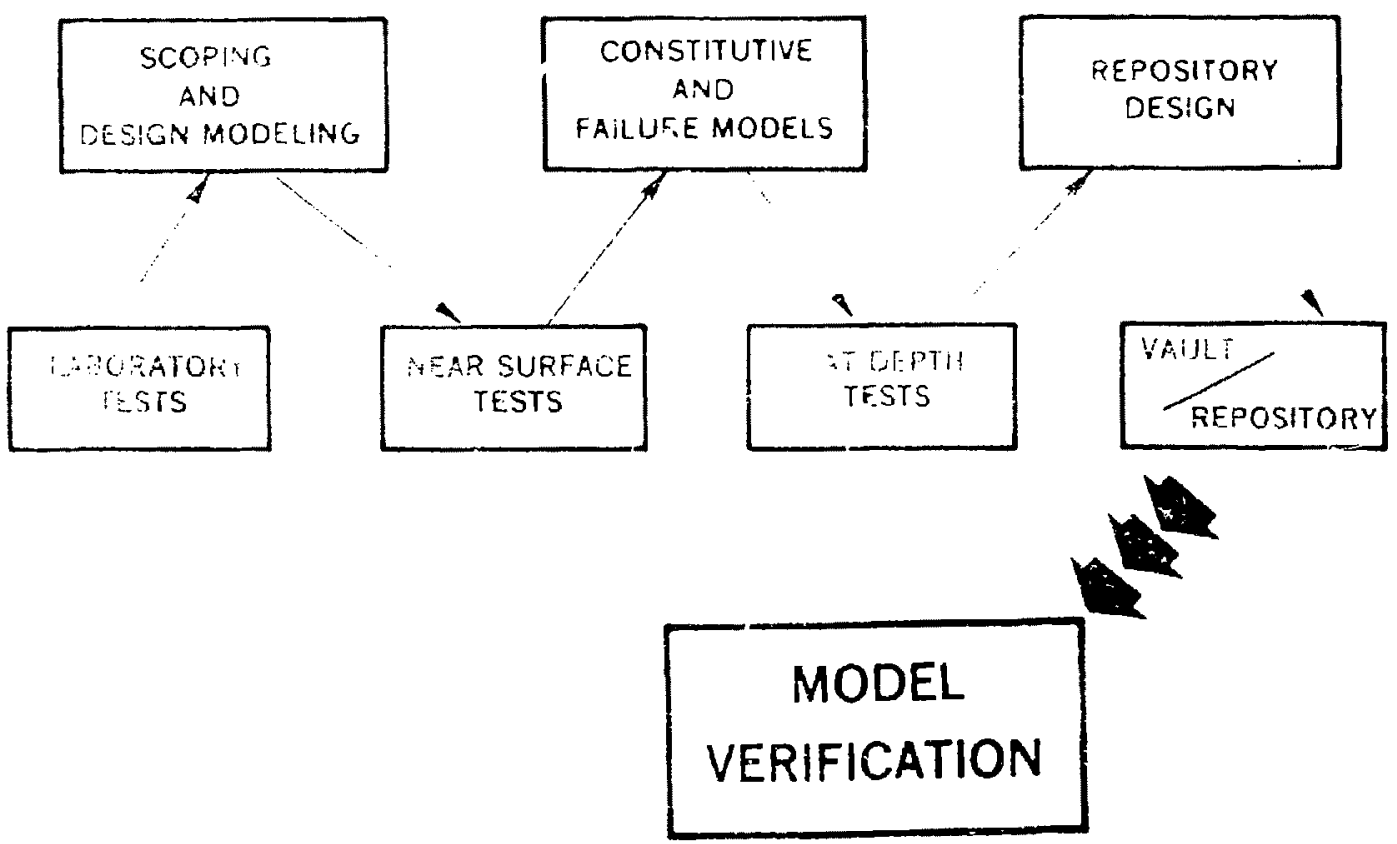




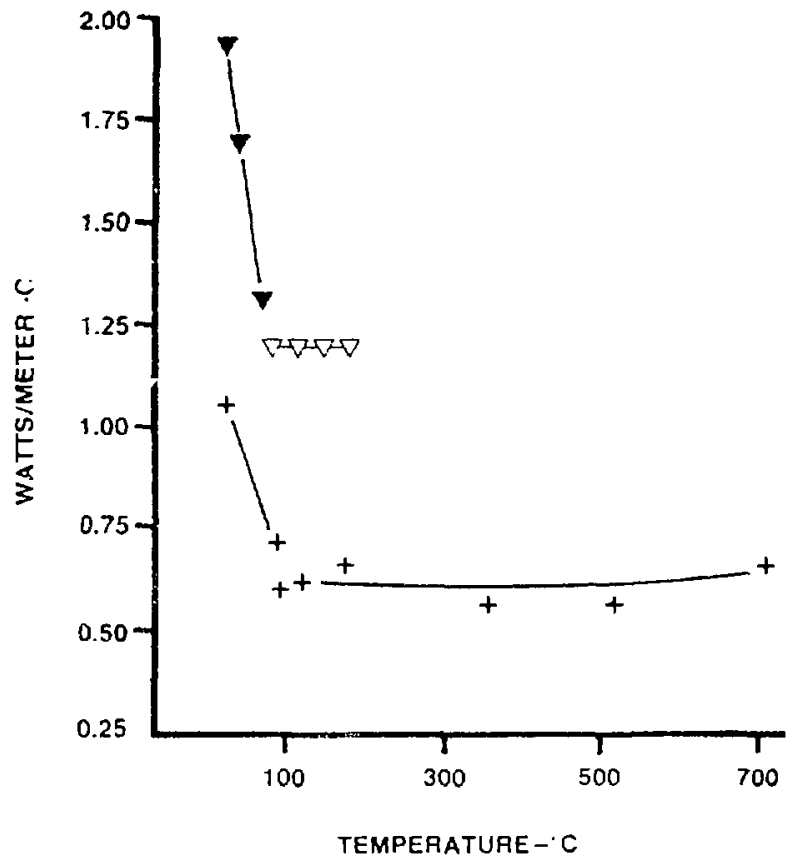

FIGURE 2

THERMAL CONDUCTIVITY - CONASAUGA SHALE 
Sampie

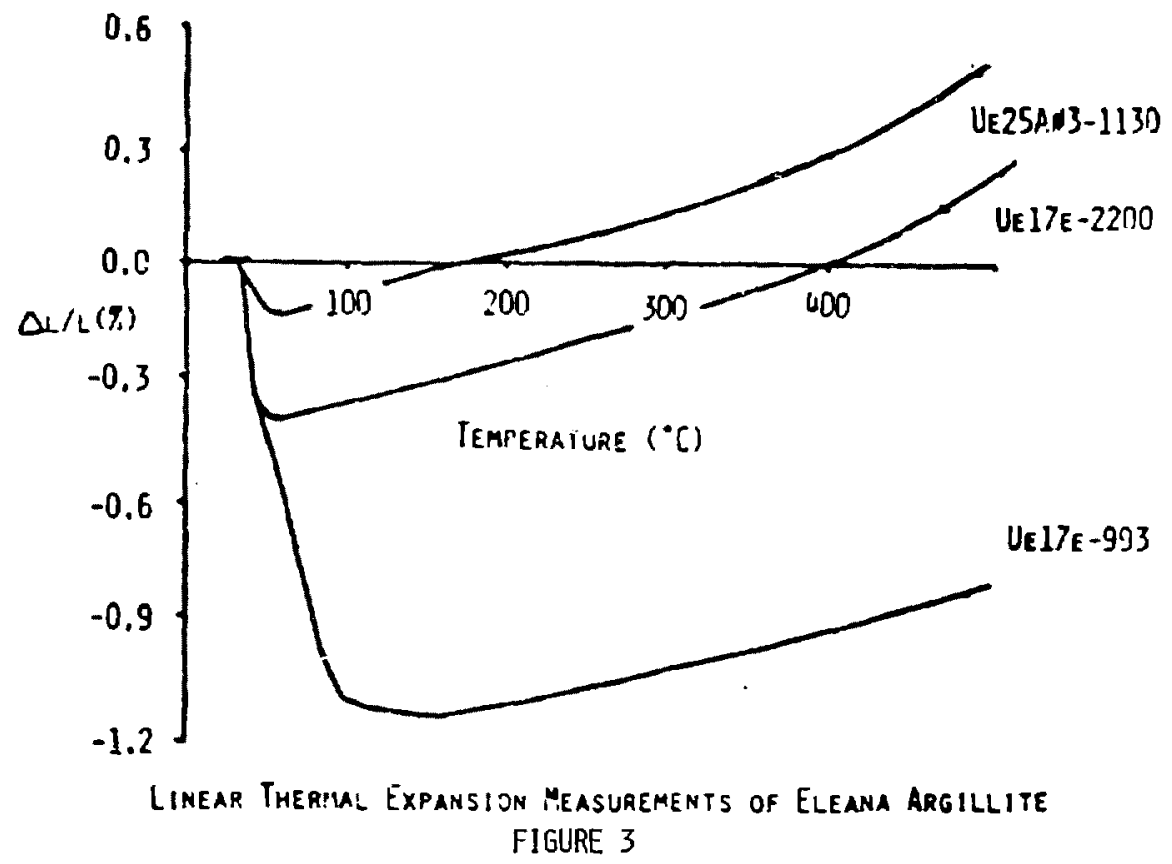




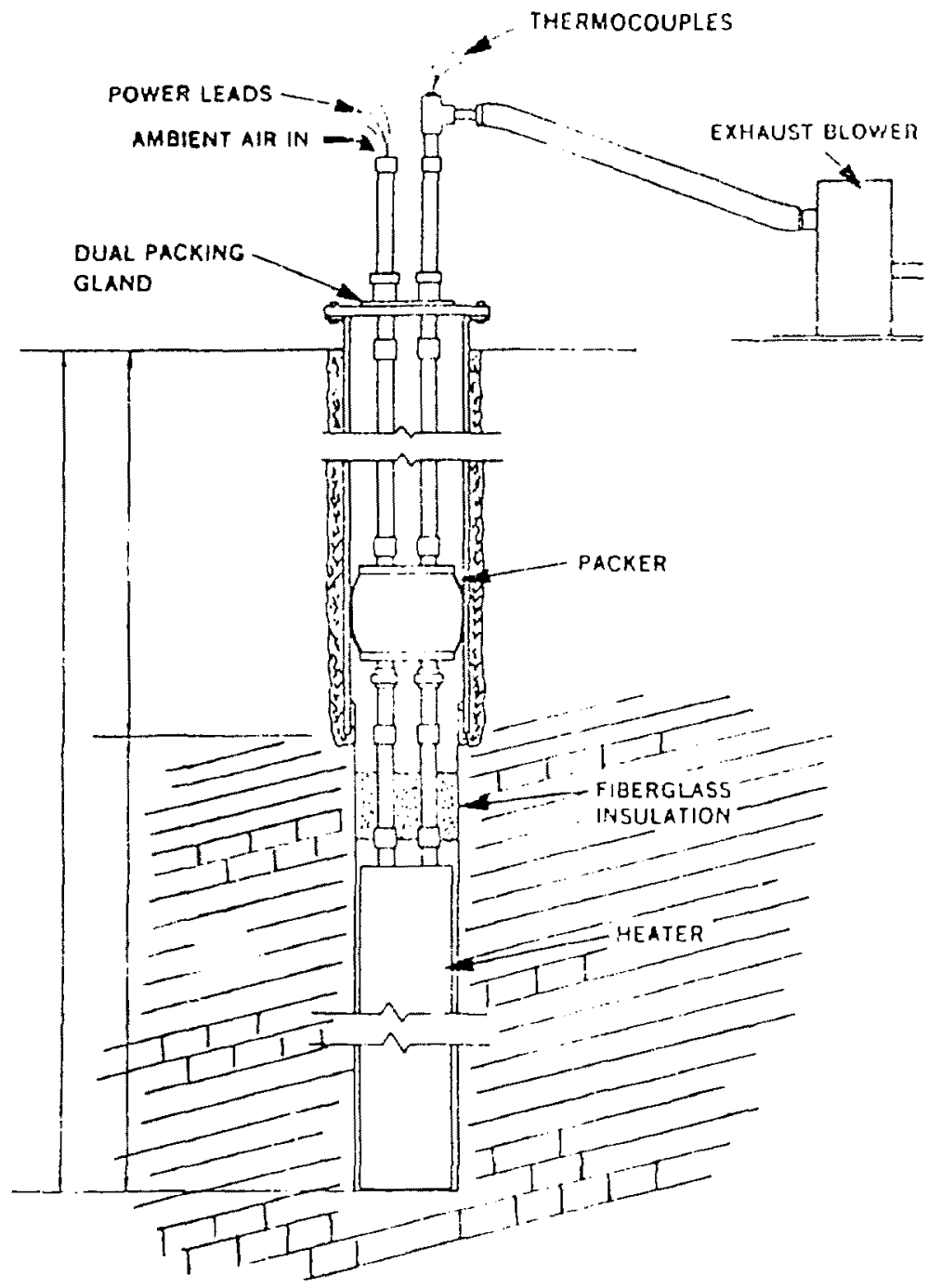

FIGURE 4

HEATER SCHEMATIC 


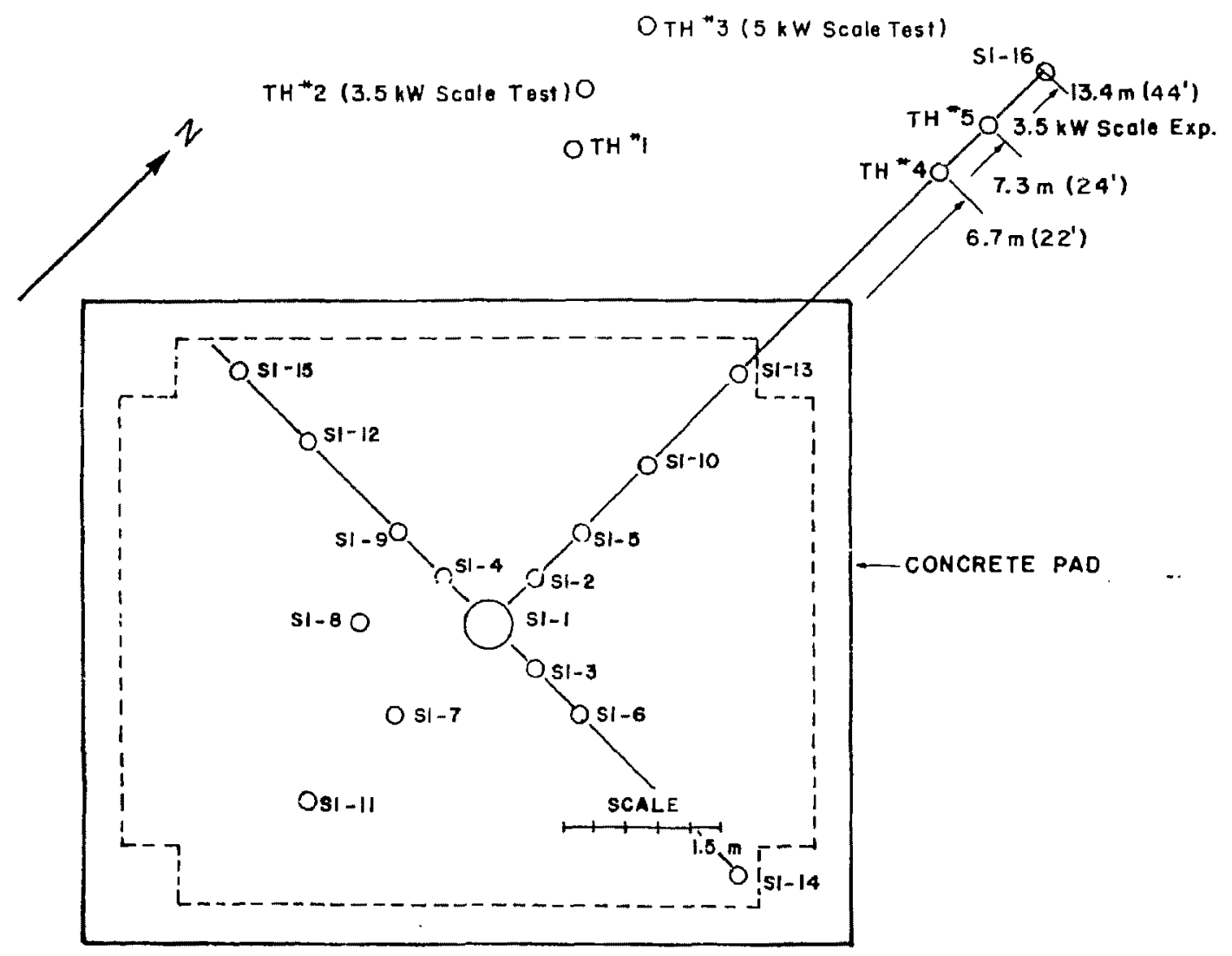

FIGURE 5--ELEANA HEATER EXPETIMENT SCHEMATIC 


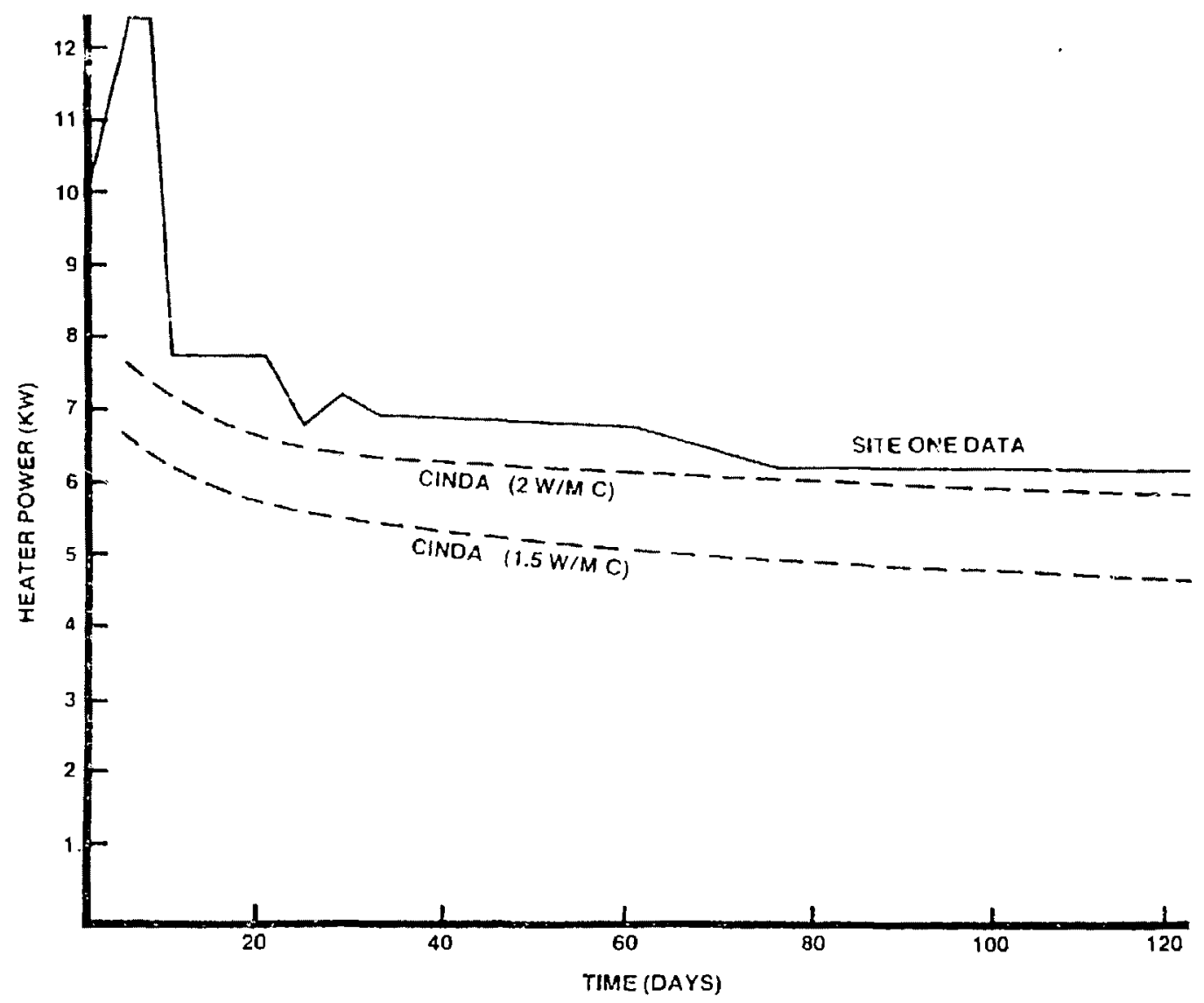

FIGURE 6--POWER DATA COHPARED WITH CINDA CALCULATIONS FOR CONASAUGA HEATER EXPERIMENT 


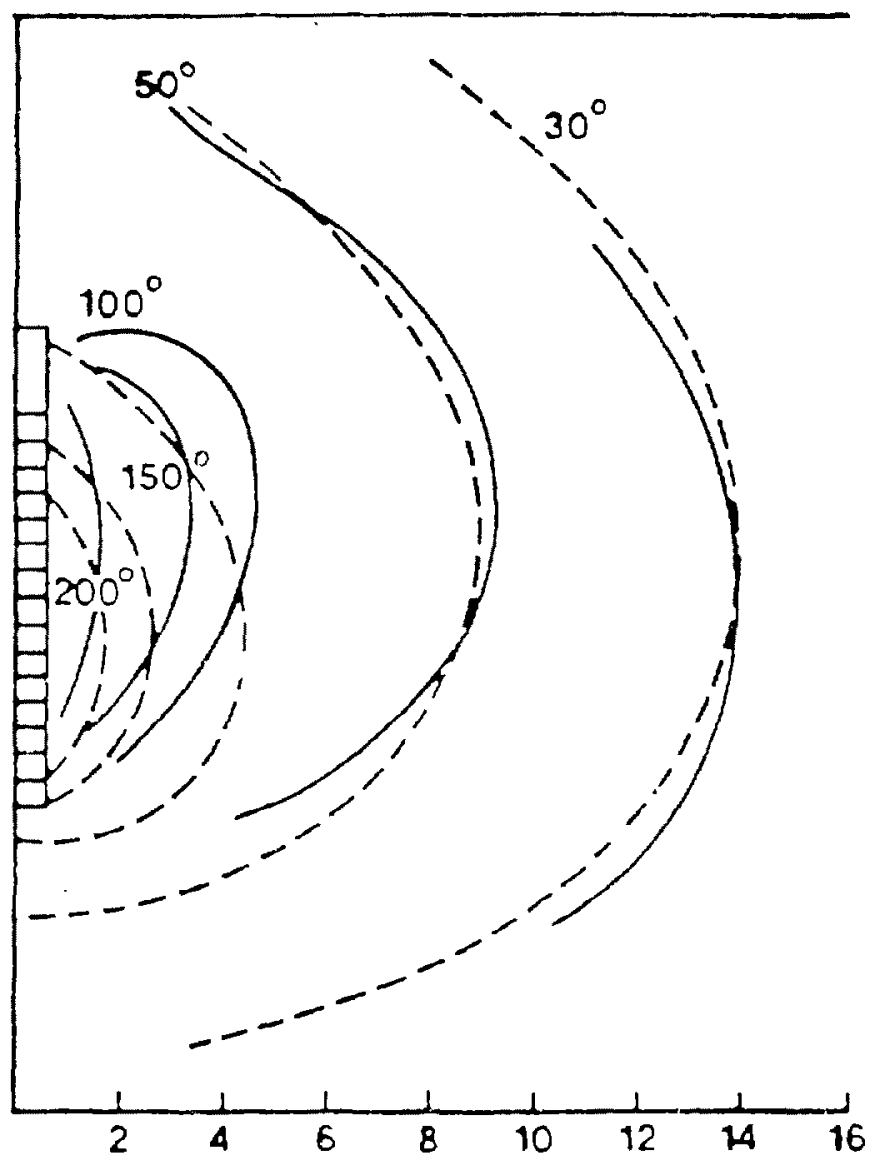

- Actual Isotherms - Site One

- - Computed Isotherms - CINDA

\author{
FIGURE 7
}

COAPARISON OF ACTUAL AND COMPUTED ISDTHERMS FOR THE CONASAUGA EXPERIMENT AT 135 DAYS 


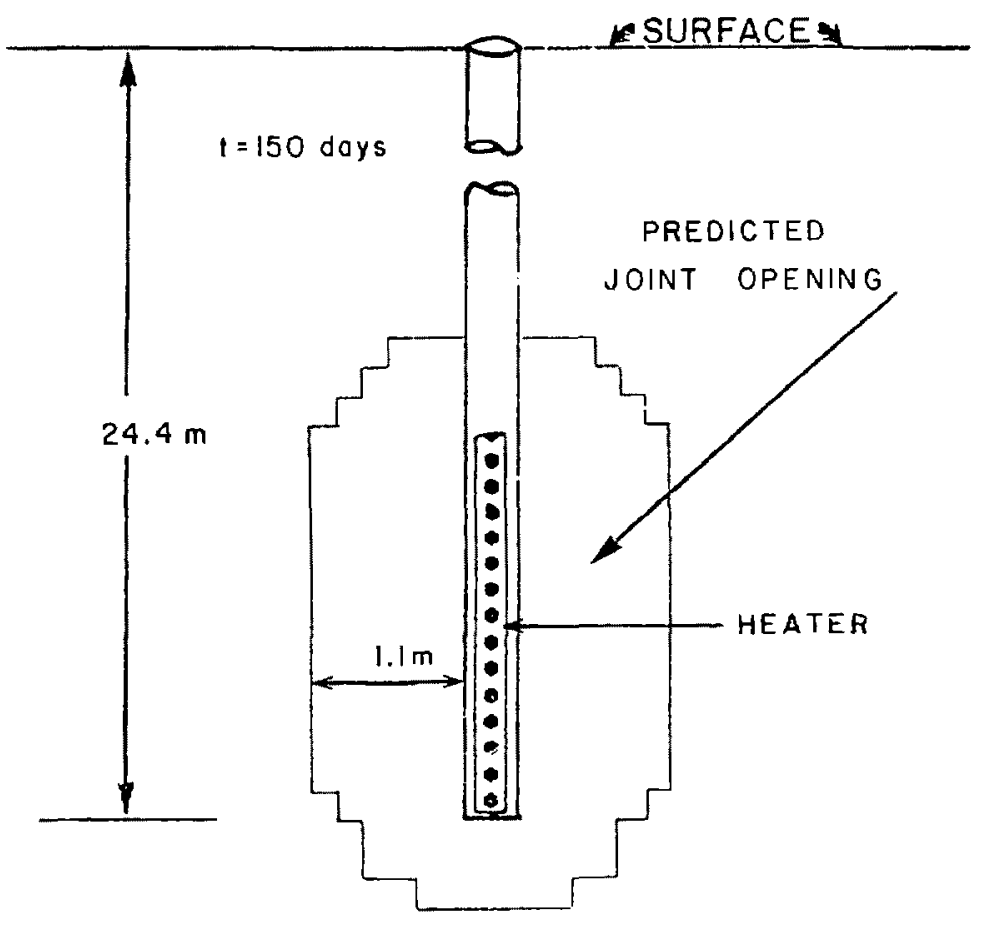

FIGURE 8

MECHANICAL MODELING RESULTS

ELEANA FULL-SCALE HEATER 